\title{
An Observational Study of the Spatial and Temporal Scales of Transient Eddy Sensible Heat Fluxes
}

\author{
AMY B. SOLOMON \\ Center for Meteorology and Physical Oceanography, Massachusetts Institute of Technology, Cambridge, Massachusetts
}

(Manuscript received 7 March 1995, in final form 23 July 1996)

\begin{abstract}
The preferred spatial and temporal scales of transient baroclinic waves that are responsible for the transport of sensible heat in midlatitudes are evaluated as a function of pressure, season, and hemisphere. The 7-level initialized ECMWF operational global analyses for the years 1980-88 are used in this study. A clear seasonal cycle in the spatial scales of the baroclinic waves is seen in the Southern Hemisphere lower troposphere. The scale selection and phase relationships of the baroclinic waves are observed to be similar in the Southern and Northern Hemispheres, indicating that the same mechanism may be responsible for the transport of heat in both hemispheres even though there are very large differences in the magnitude of the heat transported by stationary waves and in the structure of baroclinic zones. The secondary heat flux maximum at $200 \mathrm{hPa}$ is dominated by large-scale wavenumbers 2-3 in the winter and spring in both hemispheres. This may be an indication that there is a mechanism that is responsible for the heat transport at $200 \mathrm{hPa}$ that is different from the mechanism at the primary heat flux maximum, at $850 \mathrm{hPa}$ where intermediate-scale waves dominate.
\end{abstract}

\section{Introduction}

This study investigated the preferred spatial and temporal scales of transient sensible eddy heat fluxes as a function of season, height, and hemisphere. The response of eddy heat transport to changes in the seasonal forcing can give some clues as to the response of eddy heat transport to changes in climate forcing. The difference between the preferred scales of the eddy heat fluxes in the lower troposphere and those at the tropopause will shed some light on whether the same mechanism is responsible for the heat transport at the secondary heat flux maximum, observed at $200 \mathrm{hPa}$, and the primary heat flux maximum, observed at $850 \mathrm{hPa}$. The hemispheric difference in the scale selection of the eddy heat fluxes will provide insight into whether the interaction between stationary waves and transients and land-sea heating contrasts modify the characteristics of the eddies that are responsible for the heat transport.

Baroclinic eddies in the Northern Hemisphere have been observed to occur within longitudinally localized storm tracks associated with the strongest time-mean zonal wind (White 1982; Blackmon 1976). In the Northern Hemisphere the stationary waves, which arise due to zonally asymmetric thermal and topographic forcings, modify baroclinic zones by enhancing temperature gra-

Corresponding author address: Dr. Amy B. Solomon, Center for Meteorology and Physical Oceanography, Massachusetts Institute of Technology, Cambridge, MA 02139.

E-mail: amy@wind.mit.edu dients in some regions and reducing them in others. Stationary waves in the Northern Hemisphere winter are responsible for the majority of the heat transport (Kao and Sagendorf 1970; van Loon 1979). In the Southern Hemisphere winter, stationary eddies transport very little heat, due to their barotropic structure (van Loon 1979).

Despite the differences in zonal symmetry, the same zonal scale selection, eastward phase movement, and vertical phase evolution are observed in baroclinic waves in the lower troposphere in both the Southern and Northern Hemisphere winters discussed in a number of studies (Kao and Sagendorf 1970; Salby 1982; Hamilton 1983; Yu et al. 1983; Randel and Stanford 1985; Randel and Stanford 1985b, hereafter RS; Randel and Held 1991, hereafter RH). Randel and Held evaluated the wavenumber-phase speed covariance spectra for both the Northern and Southern Hemisphere in the midlatitude lower troposphere. They found that intermediate-scale waves are responsible for the transient eddy heat flux in both the Northern Hemisphere and the Southern Hemisphere in both the summer and the winter. The difference in the spectra was primarily in the magnitude and broadness of the spectral peak. This suggests that the same mechanism is responsible for the transient eddy heat transport in both the Northern and Southern Hemispheres.

This study will focus on the differences between the primary heat flux maximum in the lower troposphere and the secondary heat flux maximum at the tropopause. The secondary heat flux maximum is generally not dis- 
cussed because baroclinic growth at this level tends to be small relative to the barotropic decay of the waves. This study shows that the baroclinic waves in winter and spring at the tropopause tend to be large-scale while in summer and fall the scales are intermediate scale. This result is an indication that there may be an additional mechanism operating at the tropopause in winter and spring, other than the mechanism responsible for the growth of the intermediate-scale waves. The phase and coherence structure of the baroclinic waves is investigated as well as the decorrelation timescales of the heat fluxes themselves. The decorrelation timescale is the time over which a wave experiences baroclinic growth. Determining this timescale is important in identifying the mechanism responsible for the baroclinic growth of the wave.

Section 2 described the forecast analyses used in this study. Section 3 describes the methods used to examine the spatial and temporal scales of the waves responsible for zonal mean heat flux. Section 4 is a discussion of the observed seasonal distribution of the transient eddy heat fluxes in the troposphere. The rest of the paper focuses on the two transient eddy heat flux maxima that are observed in both hemispheres at $850 \mathrm{hPa}$ and 200 $\mathrm{hPa}$ in midlatitudes. Section 5 presents results at the primary heat flux maximum at $850 \mathrm{Hpa}$. Section 6 presents results at the secondary heat flux maximum at 200 $\mathrm{hPa}$. Section 7 summarizes the results of this study.

\section{Forecast analyses}

Global analyses from the European Centre for Medium-Range Weather Forecasts (ECMWF) have been used in this study. The analyses are created using a fourdimensional data assimilation system that combines a first guess estimate with multivariate observed data. The first guess estimate is an estimate of the current state of the atmosphere produced by a numerical weather prediction model. These global analyses are archived and maintained at the National Center for Atmospheric Research (NCAR). The analyses at NCAR are initially on a $2.5^{\circ} \times 2.5^{\circ}$ grid. The archived analyses have been interpolated to a $128 \times 64 \mathrm{~T} 42$ Gaussian grid. The analyses are available on seven pressure levels (1000, $850,700,500,300,200$, and $100 \mathrm{mb}$ ) and at two synoptic times (0001 and 1200 UTC). The analyses are initialized to bring the large-scale fields into a dynamical balance. The data used in this study cover the time period 1 December 1979 through 31 January 1989.

The analyses were created primarily for weather forecasting purposes. Therefore, it is necessary to take into account the operational changes that have been made when using an extended period of the data.

Figure 42 from Trenberth (1992) shows the poleward eddy heat flux as a function of time and latitude at 700 $\mathrm{mb}$. This figure shows that, for the time period covered in this study, the heat flux is robust and is not partic- ularly sensitive to either analysis system changes or to whether or not the fields are initialized.

Hurrell and Trenberth (1992) correlated the ECMWF temperature fields with the Microwave Sounding Unit (MSU) data. It was found that the correlations were high in regions of good radiosonde coverage and poor in regions where the analyses were heavily dependent on satellite data (the MSU data and the ECMWF data are not independent, since the MSU is used in the analyses). The poor correlations were attributed to systematic errors that are introduced into the analyses by the retrieval techniques applied to the radiance data. Trenberth (1992) also correlated the ECMWF 1000-mb temperatures with Climate Analysis Center (CAC) sea surface temperatures. These correlations were poor in all ocean regions, even when there was good data coverage. Errors are also introduced into the analyses by extrapolation of data values to pressure levels that are below ground. Between $40^{\circ}$ and $60^{\circ} \mathrm{S}$, the $1000-\mathrm{mb}$ field is extrapolated below ground in the Andes. Between $60^{\circ}$ and $40^{\circ} \mathrm{N}$, the $1000-\mathrm{mb}$ and $850-\mathrm{mb}$ fields are extrapolated below ground in the areas of the Himalayas and the Rocky Mountains.

One further note of caution in the use of this data is that the observational network is much sparser in the Southern Hemisphere than in the Northern Hemisphere. Therefore, the results for the Southern Hemisphere will be more model dependent than the results for the Northern Hemisphere.

The studies mentioned above make it clear that, although the dataset used in this study is one of the best current global analyses, the ECMWF analyses are not actual observations. The analyses at $1000 \mathrm{mb}$ and in the ocean regions must be interpreted with caution.

\section{Methods of analysis}

Two different analysis techniques are used to determine the spatial characteristics of the sensible eddy heat fluxes. The wavenumber-frequency covariance spectra is used to calculate the frequency of the waves that are responsible for the zonal mean heat flux. The timelongitude lag-correlation technique is used to calculate the decorrelation timescales of the sensible transient eddy heat fluxes.

\section{a. The wavenumber-frequency covariance spectra of the transient eddy heat fluxes}

The first technique used in this study is the wavenumber-frequency covariance spectra, coherence, and phase difference of the transient eddy heat flux. This method was developed by Hayashi (1971). The covariance spectra evaluates the wavenumber and frequency of the waves that contribute to the zonal mean heat transport. The coherence is the correlation coefficient between the wind and temperature waves that contribute to the zonal mean heat transport as a function of fre- 
quency. The phase is the phase difference between the wind and temperature waves that contribute to the zonal mean heat transport.

The spectra, coherence, and phase are calculated from the Fourier decompositions of the meridional winds and temperatures:

$$
\begin{aligned}
V^{*} & =\sum_{k}\left[C_{V}(k, t) \cos (k x)+S_{V}(k, t) \sin (k x)\right] \\
T^{*} & =\sum_{k}\left[C_{T}(k, t) \cos (k x)+S_{T}(k, t) \sin (k x) .\right.
\end{aligned}
$$

The total eddy heat flux is

$$
\begin{aligned}
V^{*} T^{*}(x, t)= & \left\{\sum_{k}\left[C_{V}(k, t) \cos (k x)+S_{V}(k, t) \sin (k x)\right]\right\} \\
& \left\{\sum_{k}\left[C_{T}(k, t) \cos (k x)+S_{T}(k, t) \sin (k x)\right]\right\} .
\end{aligned}
$$

The wavenumber covariance spectra is evaluated as $[V T](k)=0.5 \sum_{t}\left[C_{v}(k, t) C_{T}(k, t)+S_{v}(k, t) S_{T}(k, t)\right]$.

Where $[V T](k)$ is the zonal mean heat transport due to wavenumber $\mathrm{k}$, summed over all the time steps, $2 \pi /$ $k$ is generally assumed to be the localized spatial scale of the meridional wind and temperature.

This technique has been employed by Hayashi (1982), RH, and Kao and Sagendorf (1970). This analysis calculates the heat flux per wavenumber that contributes to the zonal mean. The cospectra are averaged over a season.

The spatial scales of the cospectra analyses may not be equivalent to the spatial scales of the localized wavepackets, due to the shifting of the wavenumbers to larger scales for sufficiently small wavepackets. The only terms in the cospectra that contribute to the zonal mean heat flux are the terms with the same spatial scale in temperature and meridional wind.

\section{b. The time-longitude lag-correlation diagram}

Time-longitude lag-correlation diagrams are a useful technique to provide a check on the results of the spectral decompositions. It is also a very useful technique to examine the coherence of the eddies. The time-longitude lag-correlation diagrams were devised by Fraedrich and Lutz (1987) as a means of deriving statistical estimates from Hovmöller trough and ridge diagrams. These diagrams correlate a season of eddy heat fluxes in time and longitude for a specified longitudinal basepoint. The seasonal correlations are averaged over the number of seasons.

The correlation coefficient at time lag $n \Delta t$ and zonal lag $m \Delta \lambda$, centered at basepoint longitude $\lambda$ is

$$
\begin{aligned}
\tau & (\lambda, m \Delta \lambda, n \Delta t) \\
& =\frac{\operatorname{cov}\left[V^{*} T^{*}(\lambda, t), V^{*} T^{*}(\lambda+m \Delta \lambda, t+n \Delta t)\right]}{\left[\operatorname{var} V^{*} T^{*}(\lambda, t) \operatorname{var} V^{*} T^{*}(\lambda+m \lambda, t)\right]^{1 / 2}} .
\end{aligned}
$$

The horizontal wavelength is estimated as twice the distance between the minimum and maximum correlations at zero time lag. The decorrelation timescale is estimated as the time between zero correlations of a zonally propagating wave packet. Group and phase velocities can also be estimated from these diagrams but will not be discussed in this study.

It is necessary to estimate the significance levels of the correlations in order to be able to interpret the results. A zero correlation coefficient is not equivalent to a zero in the amplitude of the wavepacket. The number of effectively independent observations, $T_{0}$, was calculated for each longitudinal basepoint, following Trenberth (1984),

$$
T_{0}=1+2 \sum_{L=1}^{N}\left(1-\frac{L}{N}\right) r(\lambda, 0, L \Delta t),
$$

where $r(\lambda, 0, L \Delta t)$ is the autocorrelation at time lag $L$ and $N$ is the number of time samples. The correlation coefficient corresponding to a significance level of $99 \%$, $r(99 \%)$, is calculated as

$$
r(99 \%)=\frac{T_{0}}{\left(T_{0}^{2}+N-2\right)^{1 / 2}} .
$$

In the Southern Hemisphere $r(99 \%)$ ranges from .20 to .25 . In the Northern Hemisphere $r(99 \%)$ ranges from .26 to .32 .

A correlation is assumed to be physically significant if the correlation is larger than the correlation of the background noise.

The time-longitude lag-correlation diagrams have been calculated using 5 years of twice-daily data. This is due to the large size of the datasets needed in the calculations. Time-longitude lag-correlation diagrams have been calculated using latitudinal averages between $40^{\circ}$ and $60^{\circ} \mathrm{N}$ and $60^{\circ}$ and $40^{\circ} \mathrm{S}$. This is because the heat fluxes have a smaller latitudinal extent than the waves that create the fluxes (Stone et al. 1982). Heat fluxes that propagate off a latitude circle cause a reduction in the correlation coefficients of the time-longitude lagcorrelation diagrams, underestimating the lifetimes of the heat fluxes. Averaging over $20^{\circ}$ of latitude did not change the results of the wavenumber-frequency covariance spectra, coherence, and phase differences.

\section{Seasonal climatology of the transient eddy heat fluxes}

Recent observations (Peixoto and Oort 1992; Trenberth 1992) have shown that, averaged over a season, there are two heat flux maxima in both the Northern Hemisphere and the Southern Hemisphere. This is seen in Figs. 1a-d. The heat fluxes peak at $50^{\circ}$ in both hemispheres and every season except the Northern Hemisphere winter, where the heat flux maxima tend to peak closer to $45^{\circ}$. The primary heat flux maximum occurs at $850 \mathrm{hPa}$, while the secondary heat flux maximum 

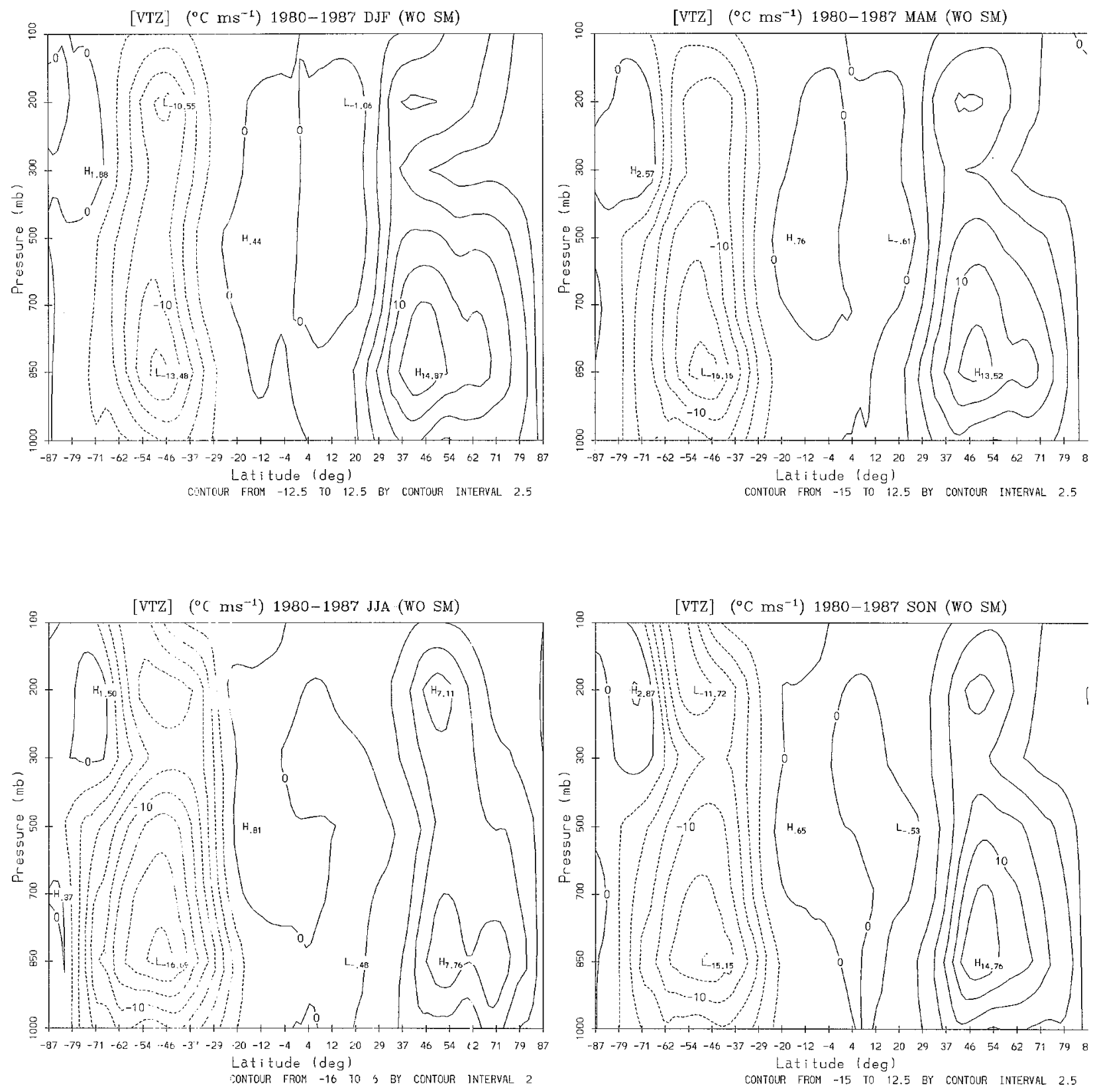

FIG. 1. The 1980-87 zonal-mean seasonally averaged transient eddy heat fluxes from the ECMWF global analyses: (a) DJF heat fluxes, (b) MAM heat fluxes, (c) JJA heat fluxes, and (d) SON heat fluxes.

occurs at $200 \mathrm{hPa}$. The fluxes above the secondary heat flux maximum decrease with height except in the Southern Hemisphere spring when the polar vortex is breaking up. In the Northern Hemisphere, the maxima are of the same order for all seasons except in the summer season, where the primary maximum is reduced by $50 \%$ and the secondary maximum is reduced by $40 \%$ relative to the other seasons. This is coincident with the $50 \%$ reduction in the midlatitude temperature gradients from winter to summer (Trenberth 1992). In the Southern Hemisphere winter, the primary maximum is strongest and the secondary maximum is weakest in the Southern Hemisphere winter. The secondary maximum is strongest in the Southern Hemisphere spring.

The structure and magnitude of the transient eddy forcing of the mean temperature, the divergence of the eddy heat flux, is relatively unchanged from fall to spring in both hemispheres. This is interesting considering that the stationary waves in the Northern Hemisphere are responsible for the majority of the heat flux during winter, while in the Southern Hemisphere the stationary waves transport very little heat. The station- 

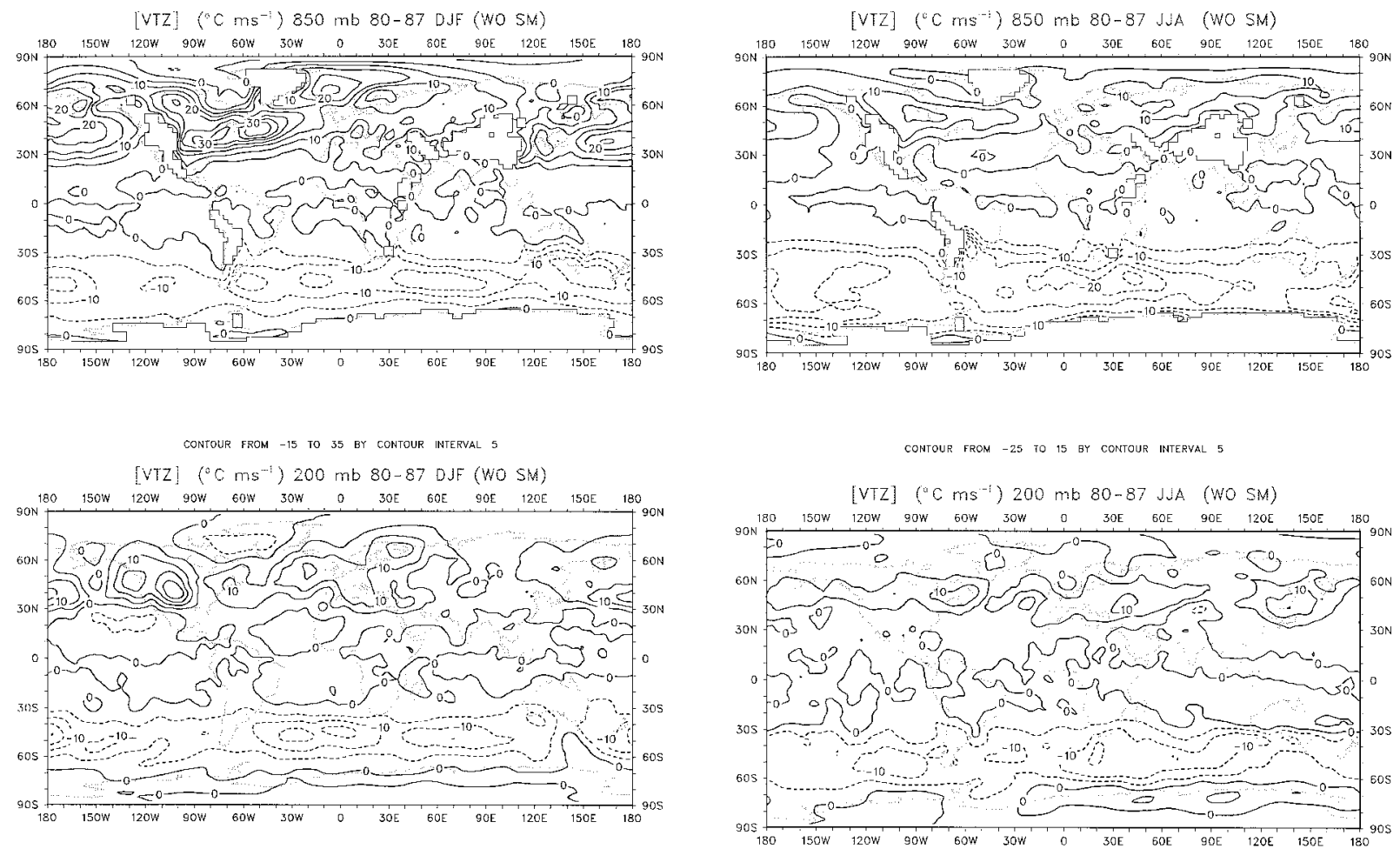

CONTOUR FHOM -20 TO 20 BY CONTOUR INTERVAL

FIG. 2. The 1980-87 DJF averaged transient eddy heat flux horizontal cross sections: (a) $850-\mathrm{hPa}$ heat fluxes, (b) $200-\mathrm{hPa}$ heat fluxes.

FIG. 3. The 1980-87 JJA averaged transient eddy heat flux horizontal cross sections: (a) $850-\mathrm{hPa}$ heat fluxes, (b) 200-hPa heat fluxes.

ary waves increase mean temperature gradients in longitudinally localized regions and decrease them in others. This changes the forcing of the transient eddies. Therefore, it is interesting that the zonal mean of the transient eddy forcing is so similar between the Northern and Southern Hemisphere winters. In the summer season in both hemispheres, the transient eddy forcing of the mean temperature is greatly reduced.

The longitudinally localized nature of the winter and summer transient eddy heat fluxes that contribute to the zonal mean at $850 \mathrm{hPa}$, the pressure level of the primary heat flux maximum, is seen in Figs. 2a and 3a. The winter and summer heat fluxes at $200 \mathrm{hPa}$, the level at which the secondary heat flux maxima is observed, are shown in Figs. $2 b$ and $3 b$. The primary heat flux maxima, at $850 \mathrm{hPa}$, occurs primarily over the ocean in stormtrack regions where the zonal wind and meridional temperature gradients are a maximum. Stormtracks are seen in the Southern Hemisphere east of South America, due to the Antarctic Continent's influence on the Circumpolar Current. The secondary heat flux maxima at the tropopause, $200 \mathrm{hPa}$, also occurs in regions where the zonal wind is a maximum. At the tropopause, the relationship between the meridional temperature gradients and the stormtracks is not as clear as it is at the 850-hPa level. Therefore, the secondary heat flux maximum is not clearly related to the maximum meridional

temperature gradients. Even though the Southern Hemisphere heat fluxes have a more zonal distribution relative to the Northern Hemisphere, the zonal mean of the heat fluxes and the forcing of the zonal mean temperature by the eddy heat fluxes are very similar in both hemispheres, except in the summer season.

\section{Observations at the primary heat flux maximum}

The primary heat flux maximum by baroclinic waves causes a conversion of mean available potential energy to eddy potential energy. This downgradient transport of heat reduces the diabatically forced temperature gradients in midlatitudes. These fluxes have been modeled by studies such as Simmons and Hoskins (1978, hereafter SH) and observed by RS. Randel and Held (1991) used 9 yr of ECMWF global analyses to calculate the wavenumber-phase speed covariance spectra of the heat fluxes in the midlatitude lower troposphere for both the Northern and Southern Hemispheres and for both the summer and winter season. The results of RH show that despite the large differences in stationary wave forcing and baroclinic zones, the transient eddy heat transport in the Northern and Southern Hemisphere lower troposphere winter have similar scale selection and phase 

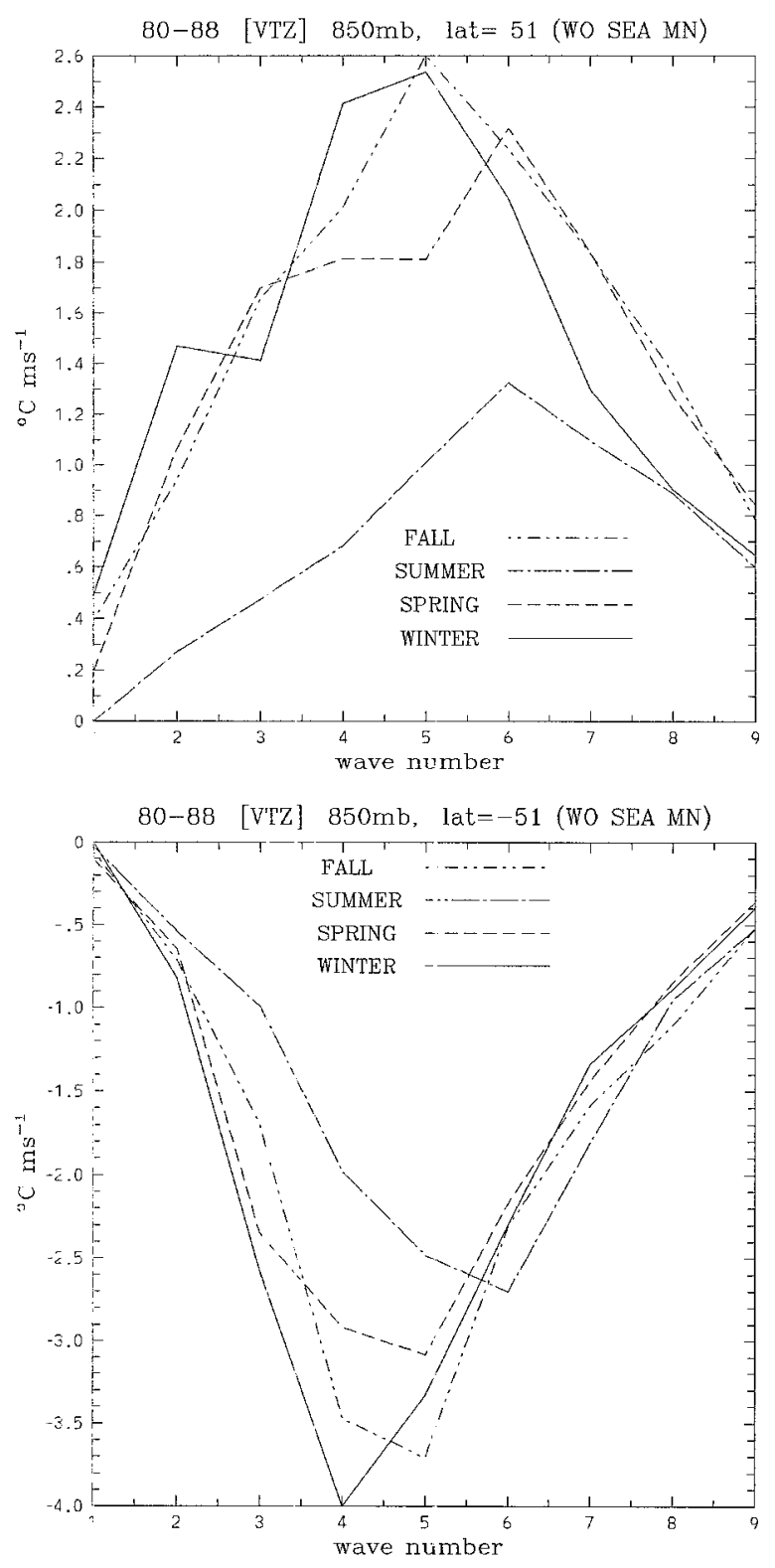

FIG. 4. The 1980-88 zonal mean transient eddy heat fluxes at 850 $\mathrm{hPa}$, with seasonal means removed, as a function of zonal wavenumber: (a) heat fluxes at $51^{\circ} \mathrm{N}$, (b) heat fluxes at $51^{\circ} \mathrm{S}$.

speeds. The winter covariance spectra are sharply peaked and dominated by the heat transport due to the intermediate-scale waves. The summer covariant spectra are also dominated by the heat transport due to intermediate-scale waves. The Northern Hemisphere summer spectra has much less heat transport per wavenumber and exhibits a broad peak. Randel and Held attribute this broad peak to the more spatially localized features in the Northern Hemisphere as opposed to the Southern Hemisphere where the medium-scale waves tend to have a more hemispheric extent.

A closer inspection of the waves responsible for the
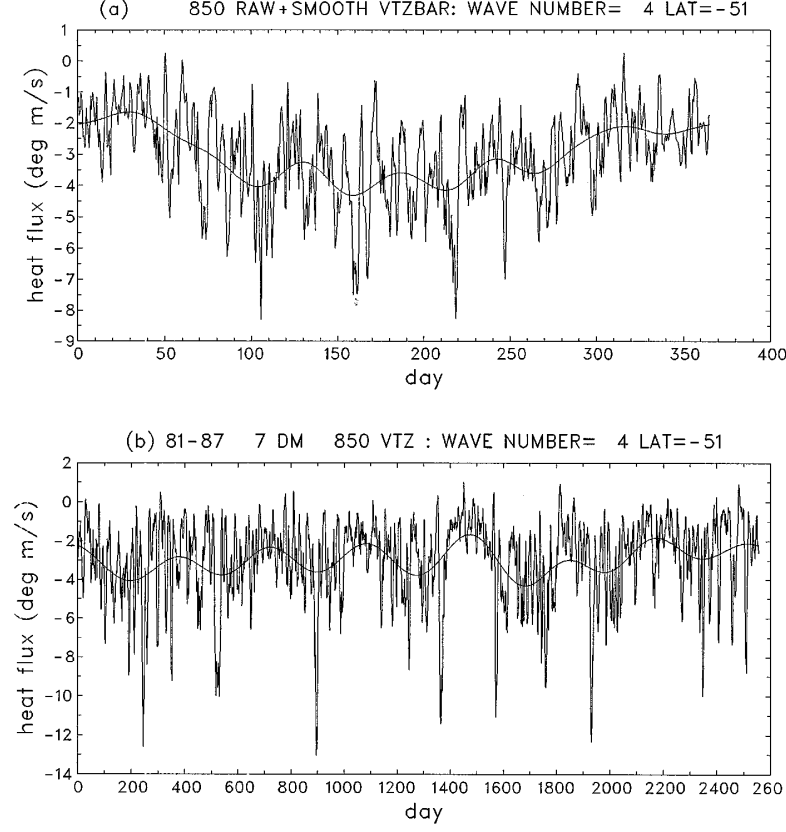

FIG. 5. Time series of the zonal mean transient eddy heat fluxes at $850 \mathrm{hPa}$ due to wavenumber 4 at $51^{\circ} \mathrm{S}$. The smooth curve is the raw data smoothed by applying a weighted Fourier series. (a) The 1980-88 annual cycle of the transient eddy heat fluxes. (b) The 198187 twice-daily transient eddy heat fluxes smoothed by applying a 7-day running mean average.

heat transport in the lower troposphere shows that there is a seasonal cycle in the preferred scale of the baroclinic waves. Figure $4 \mathrm{a}$ shows the wavenumber covariance heat flux spectra at $850 \mathrm{hPa}$ in the Northern Hemisphere for each season with the seasonal mean removed. Figure $4 \mathrm{~b}$ is the same calculation for the Southern Hemisphere. The seasonal cycle is seen most clearly in the Southern Hemisphere. The winter heat flux is primarily due to wavenumber 4 . The fall and spring seasons are less sharply peaked and are a maximum at wavenumber 5 . The summer heat flux is primarily due to heat transport by wavenumber 6 . This is true for all pressure levels in the lower troposphere (500 hPa and below).

The time series of the heat fluxes at $51^{\circ} \mathrm{S}$ due to transport by wavenumber 4 at $850 \mathrm{hPa}$ is displayed in Fig. 5b. The time series is for twice daily data for the years 1981-87. A 7-day running mean has been applied to the time series to smooth the small-scale fluctuations and to make the interannual variations clearer. The annual cycle of the $1980-88$ heat fluxes at $51^{\circ} \mathrm{S}$ by wavenumber 4 at $850 \mathrm{hPa}$ is displayed in Fig. 5a. The smooth curves in Figs. 5a and 5b are the 7-yr time series and the annual cycle after a weighted Fourier smoother has been applied. The time series of the heat fluxes at $51^{\circ} \mathrm{S}$ due to transport by wavenumber 6 at $850 \mathrm{hPa}$ is displayed in Fig. 6b. The annual cycle of the 1980-88 heat fluxes at $51^{\circ} \mathrm{S}$ by wavenumber 6 at $850 \mathrm{hPa}$ is displayed in Fig. 6a. The same smoothers have been applied to the wavenumber 4 and wavenumber 6 time series. 

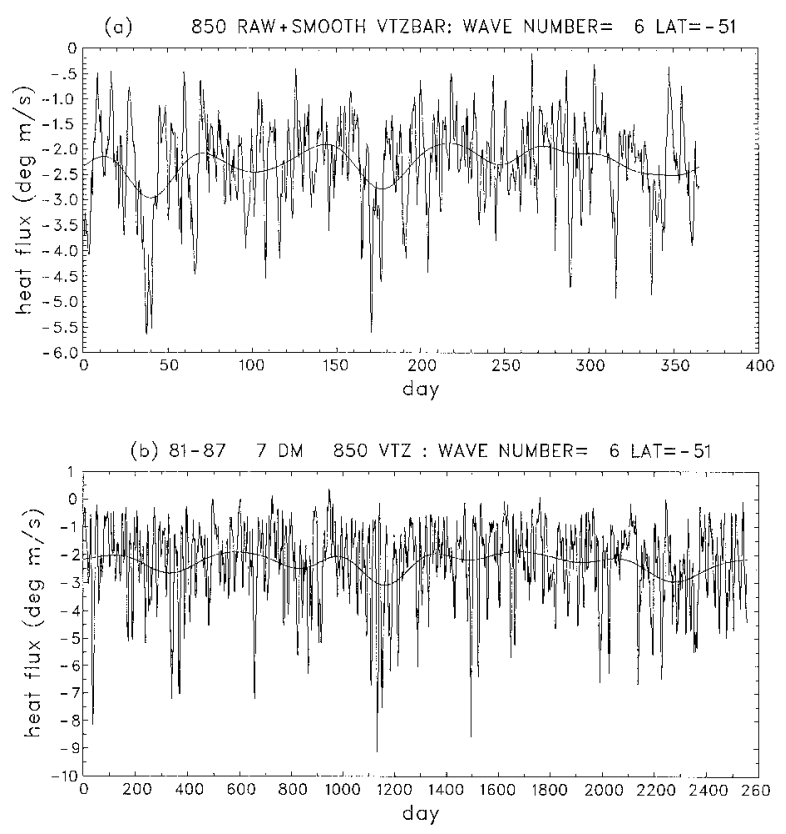

FIG. 6. Time series of the zonal mean transient eddy heat fluxes at $850 \mathrm{hPa}$ due to wavenumber 6 at $51^{\circ} \mathrm{S}$. The smooth curve is the raw data smoothed by applying a weighted Fourier series. (a) The 1980-88 annual cycle of the transient eddy heat fluxes. (b) The 198187 twice-daily transient eddy heat fluxes smoothed by applying a 7-day running mean average.

The heat fluxes due to wavenumber 4 show an annual cycle with larger heat fluxes in the winter and smaller heat fluxes in the summer. The heat fluxes due to wavenumber 6 have no clear annual cycle, although a hint of an annual cycle can be seen in the 7-yr time series. It appears that instead of a seasonal cycle in the spatial scale of the baroclinic wave that is responsible for the majority of the heat transport, as suggested by the wavenumber spectra figures, what is actually occurring is an annual cycle in the magnitude of the heat flux due to wavenumber 4 while the heat flux due to wavenumber 6 is relatively independent in the change in seasonal forcing.

Figures $7 \mathrm{~b}$ and $\mathrm{d}$ show the phase difference between the perturbation wind and temperature that are responsible for the zonal mean heat transport in the $850-\mathrm{hPa}$ Southern Hemisphere winter and summer season, respectively. Figures $7 \mathrm{a}$ and $\mathrm{c}$ show the coherence between the perturbation wind and temperature that are responsible for the zonal mean heat transport in the $850-\mathrm{hPa}$ Southern Hemisphere winter and summer season, respectively. The shaded region in the coherence plots show the zonal wavenumber and frequencies at which the coherence is greater than or equal to 0.8 . The shaded region in the phase plots show the zonal wavenumber and frequencies at which the phase difference is between $-160^{\circ}$ and $-140^{\circ}$. Wavenumbers $4-7$ are the most highly coherent wavenumbers in both the summer and winter seasons. These waves are eastward propagating with frequencies between 10 days, for wavenumber 4 , and 3 days, for wavenumber 7 . The smallest phase differences for these highly coherent wavenumbers shifts from wavenumbers 5-6 in summer to wavenumbers 4-6 in winter. This is clearly seen in Figs. $7 b$ and $d$. This is consistent with the shift in the seasonal spatial scales of the wavenumbers seen in Fig. 4b. This result suggests that the shift in spatial scales from 4-6 in winter to 56 in summer is due to a change in the phase differences between the perturbation winds and temperatures and not due to the perturbations becoming less coherent in the summer season. This result is also found in the Northern Hemisphere. This result is consistent with the annual cycles seen in Figs. 5a and 6a.

It was not clear when this study began whether the spatial scales calculated from the covariance spectra method were consistent with the localized scales of the transient eddy heat fluxes. This uncertainty is due to the tendency of the covariance spectra method to shift the zonal scale of a localized wavepacket to longer wavelengths. Time-longitude lag-correlation (TLLC) diagrams were calculated to determine if the spectra results were in fact consistent with the localized scales of the heat fluxes. It was found that the spatial scales of the waves calculated by the two different methods were consistent except for the waves at the 200-hPa level in winter and spring. At $200 \mathrm{hPa}$, in the winter and spring seasons, the large-scale waves that create the perturbation winds and temperatures that are responsible for the majority of the heat transport are less coherent than the intermediate-scale waves, which are highly coherent. Therefore, the TLLC diagrams for these seasons showed that the heat fluxes had a spatial scale of an intermediatescale wave while the wavenumber spectra method showed that the spatial scales were much larger. This will be discussed further in the next section.

The TLLC is used to calculate the average lifetime of a heat flux event. Figures $8 \mathrm{a}$ and $\mathrm{b}$ show the TLLC diagrams for the winter and summer seasons in the Southern Hemisphere at $850 \mathrm{hPa}$. If the $99 \%$ statistical correlation calculated in the discussion on methods is used to estimate the lifetime of the flux, then the average lifetime would be approximately 3 days. If the lifetime of the heat flux is estimated as the time between the zero correlations in the summer season TLLC diagram, then the estimated lifetime would be closer to 6 days. An estimate of the lifetime of the heat fluxes in the winter season as the time interval between zero correlations would be closer to 8 days. The $99 \%$ statistical correlation may be too strict a limit for the lifetimes. The difference between 3 days and 8 days is very large and would suggest different mechanisms for the growth of the baroclinic waves. The modeled lifecycle study of $\mathrm{SH}$ and the observed lifecycle study of RS suggest that the lifetime of a heat flux due to baroclinic instability would be close to 8 days. Figures $9 \mathrm{a}$ and b are Hovmöller diagrams for January and July 1980 at $850 \mathrm{hPa}$. The heat fluxes for this month are typical of July and 

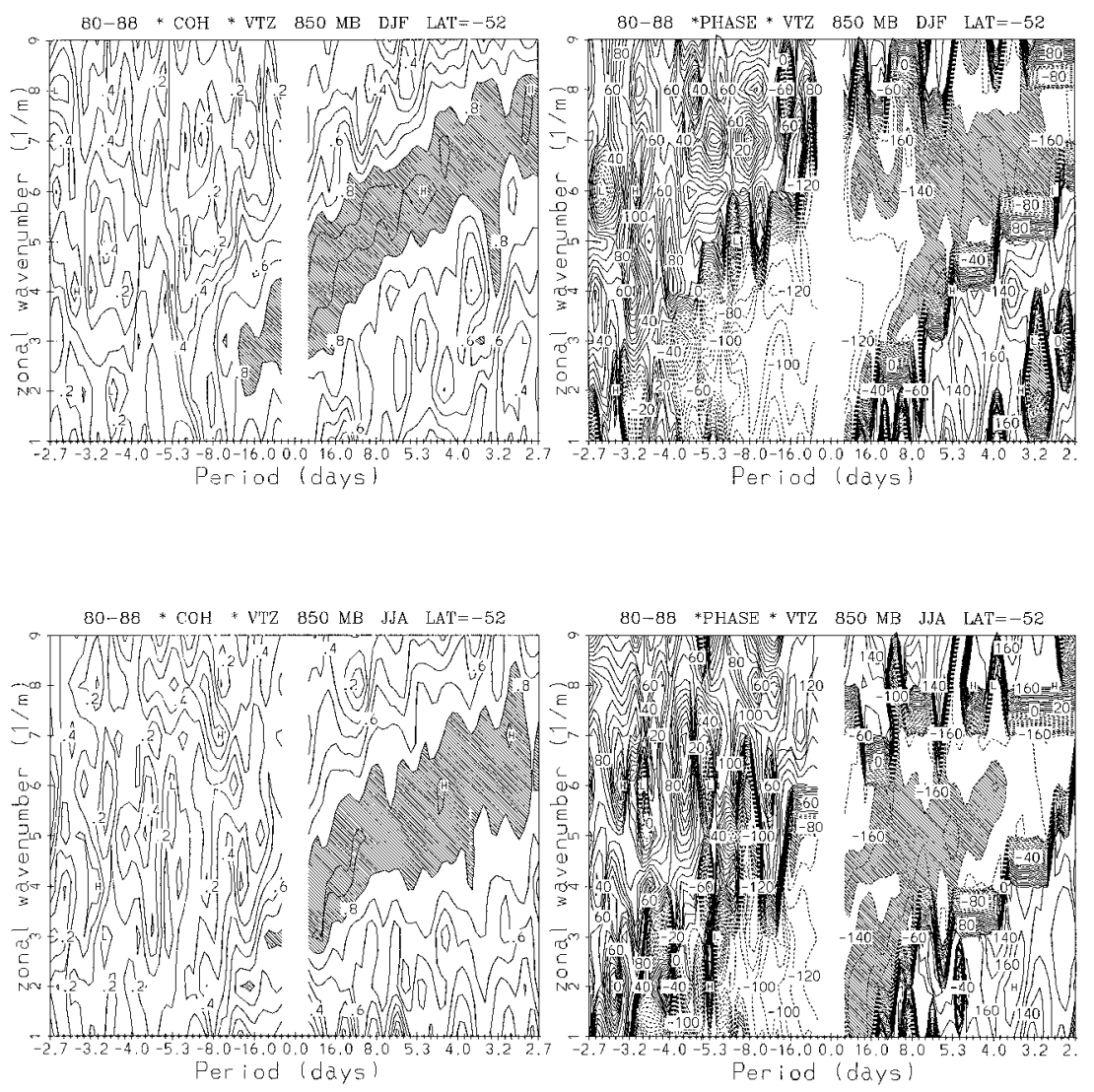

FIG. 7. The $1980-8851^{\circ} \mathrm{S}$ seasonally averaged wavenumber-frequency covariance of the transient eddy heat fluxes at $850 \mathrm{hPa}$. (a) Summer coherence (shaded region indicates coherence greater than 0.8). (b) Summer phase difference (shaded region indicates phase differences between $-160^{\circ}$ and $-140^{\circ}$ ). (c) Winter coherence [shading as in (a)]. (d) Winter phase difference [shading as in (b)].

January heat fluxes in the Southern Hemisphere. The Southern Hemisphere stormtrack between $45^{\circ} \mathrm{W}$ and $90^{\circ} \mathrm{E}$ can be seen clearly in Fig. 9b. This plot shows that the heat fluxes tend to persist for less than 6 days in January but in July heat fluxes tend to have a longer lifetime that is closer to 8 days. Therefore, estimating the lifetimes of the heat fluxes implies that the $99 \%$ statistical correlation underestimates the lifetimes. The lifetimes of the heat fluxes are actually closer to the lifetimes of the studies by SH and RS. Figure 10 is the Hovmöller diagram for January 1981 at $850 \mathrm{hPa}$ and $51^{\circ} \mathrm{N}$. This figure suggests that the lifetimes of the transient eddy heat fluxes tend to persist for a shorter time in the Northern Hemisphere winter than in the Southern Hemisphere winter (Fig. 9b). There is significant interannual variability in the lifetimes and stormtracks in the Northern Hemisphere (results not shown). It is difficult to determine the average lifetime of a heat flux event by one month of data. The 5-yr statistical estimate of the lifetime from the TLLC diagram for the 1981-85 Northern Hemisphere winter season (Fig. 8c) shows that the average lifetime is close to 6 days, when calculated as the time between the zero correlations along the maximum correlation line.

\section{Observations at the secondary heat flux maximum}

The secondary heat flux maximum at $200 \mathrm{hPa}$ is important in the maintenance of the temperature structure of the upper troposphere and the magnitude of the zonal mean jet at the tropopause. Since the temperature gradients at the tropopause are small (Trenberth 1992), very little available potential energy is converted to eddy potential energy by these fluxes. This secondary heat flux maximum does not show up in the study of Kao and Sagendorf (1970). In baroclinic lifecycle studies, such as $\mathrm{SH}$, the secondary heat flux maximum is typically neglected because of the large decay of the barotropic waves at the tropopause that is responsible for the strengthening and barotropization of the zonal mean wind. The wavenumber spectra of the heat flux at the secondary maximum shows that the heat fluxes cannot be explained completely by the results of the lifecycle 

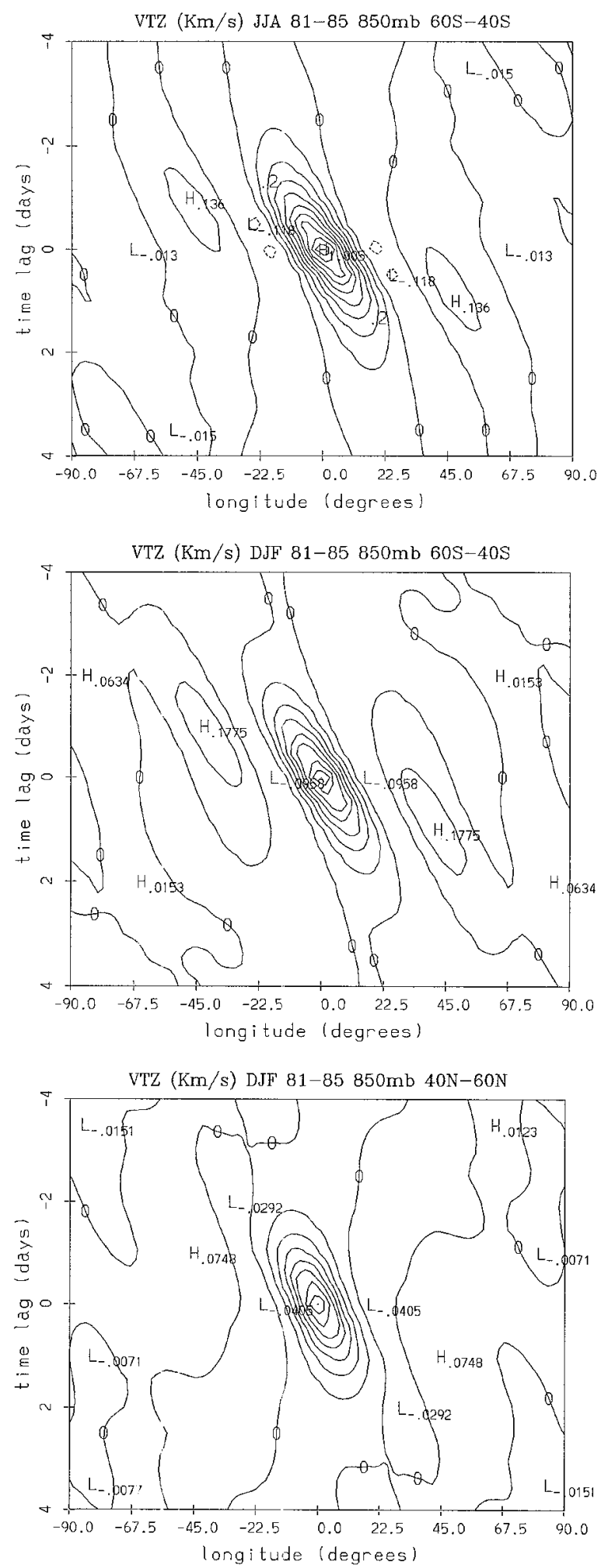

FIG. 8. Seasonally averaged 1981-85 850-hPa TTLC diagram: (a) $60^{\circ} \mathrm{S}-40^{\circ} \mathrm{S}$ JJA season, (b) $60^{\circ} \mathrm{S}-40^{\circ} \mathrm{S}$ DJF season, and (c) $40^{\circ}-60^{\circ} \mathrm{N}$ DJF season.
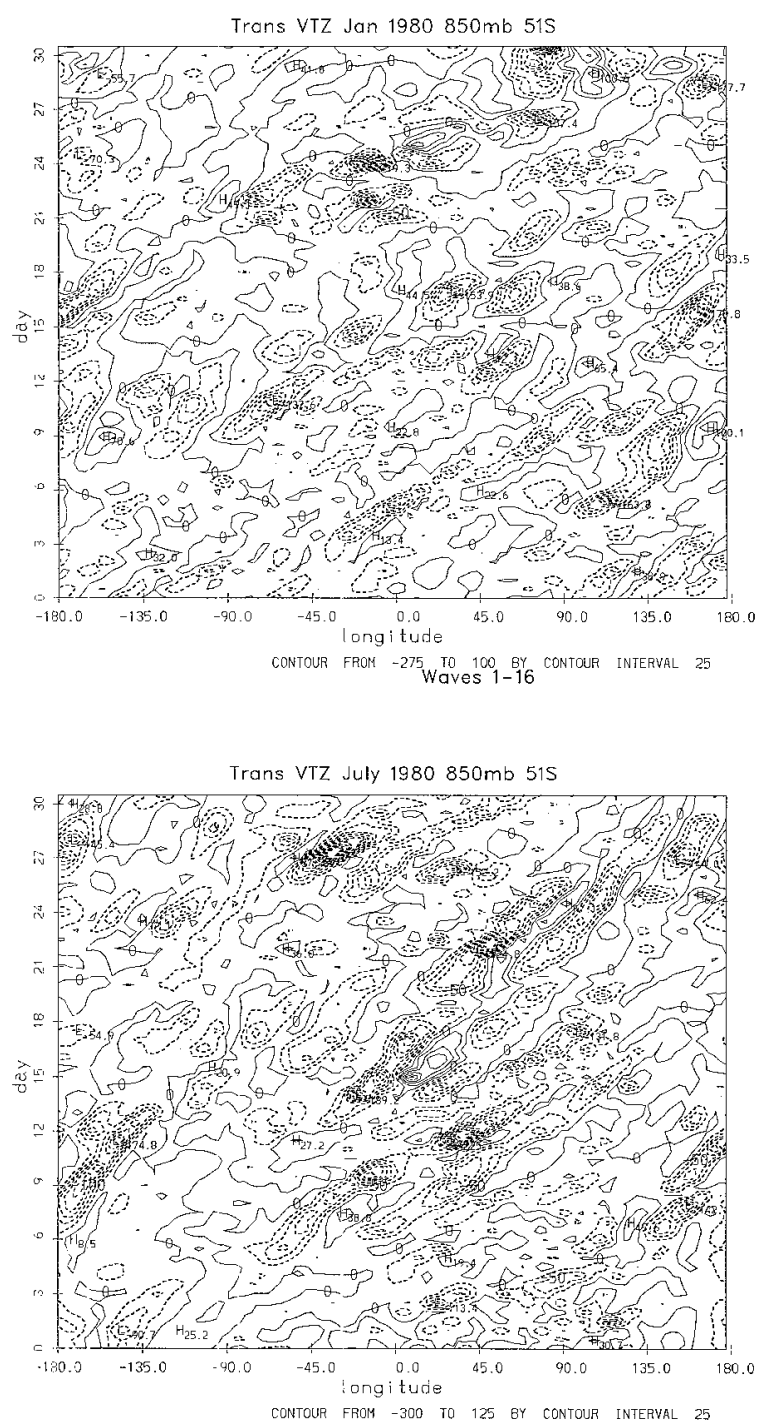

Fig. 9. Hovmöller diagram at $850 \mathrm{hPa}$ and $51^{\circ} \mathrm{S}$ (in units of $\mathrm{mK}$ $\mathrm{s}^{-1}$ ): (a) January and (b) July.

studies because these studies focus on the role of intermediate-scale waves.

Figures 11a and b show the wavenumber covariance spectra of the transient eddy heat fluxes at the secondary heat flux maximum at $51^{\circ} \mathrm{N}$ and $51^{\circ} \mathrm{S}$. In the summer and fall seasons the spatial scales of the waves are consistent with the spatial scales that were found in the lower troposphere. Wavenumber 6 dominates in the summer and wavenumber 5 dominates in the fall. The winter and spring seasons are dominated by large-scale wavenumbers $2-3$. These results have been found in both the Northern and Southern Hemispheres.

The time series of the heat fluxes at $51^{\circ} \mathrm{S}$ due to transport by wavenumber 2 at $200 \mathrm{hPa}$ is displayed in Fig. 12b. The time series is for twice daily data for the years 1981-87. The annual cycle of the 1980-88 heat fluxes at $51^{\circ} \mathrm{S}$ by wavenumber 2 at $200 \mathrm{hPa}$ is displayed 


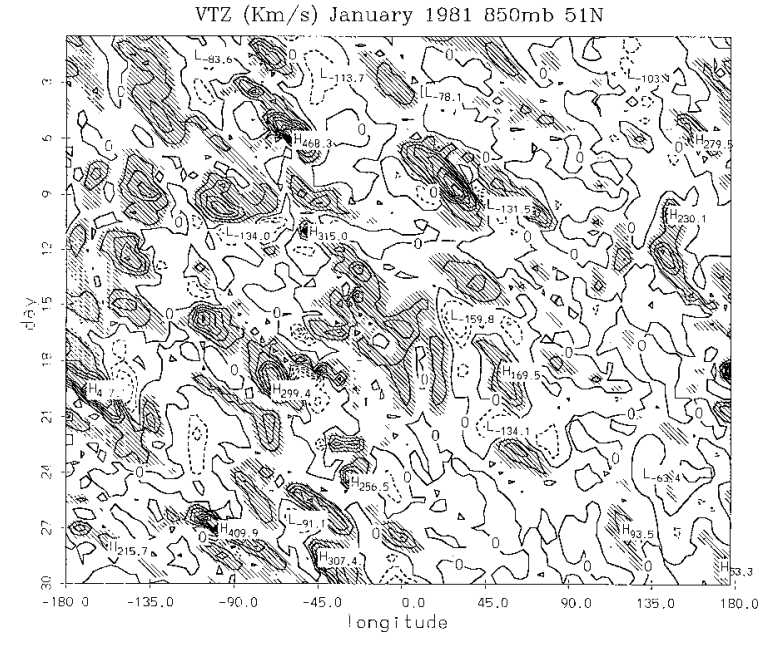

FIG. 10. Hovmöller diagram for January 1981 at $850 \mathrm{hPa}$ and $51^{\circ} \mathrm{N}$ (in units of $\mathrm{mK} \mathrm{s}^{-1}$ ) (shaded region indicates fluxes greater than 25 $\left.\mathrm{mK} \mathrm{s}^{-1}\right)$.

in Fig. 12a. The time series of the heat fluxes at $51^{\circ} \mathrm{S}$ due to transport by wavenumber 4 at $200 \mathrm{hPa}$ is displayed in Fig. 13b. The annual cycle of the 1980-88 heat fluxes at $51^{\circ} \mathrm{S}$ by wavenumber 4 at $200 \mathrm{hPa}$ is displayed in Fig. 13a. The same smoothers have been applied to the time series in Figs. 12a, 12b, 13a, and $13 \mathrm{~b}$ as were applied to the time series in Figs. 5a, 5b, $6 \mathrm{a}$, and $6 \mathrm{~b}$. Wavenumber 2 has an annual cycle where very little heat is transported in the summer and fall. In the winter and spring seasons the variance of the heat fluxes increases and the seasonal heat fluxes increase to $-3.5^{\circ} \mathrm{m} \mathrm{s}^{-1}$. Figure $13 \mathrm{~b}$ shows that wavenumber 4 has no annual cycle. The 7-year time series shows an initial seasonal cycle for 1981 and then no seasonal cycle for years 1982-87. This is interesting considering the strong seasonal cycle that was observed in the lower troposphere for heat fluxes due to wavenumber 4 (Fig. 5b), if the wavenumber 4 variance at the tropopause is due to waves that propagate up from the lower troposphere.

Figures $14 \mathrm{a}$ and $\mathrm{b}$ are the coherence and phase difference plots for the summer season at the secondary heat flux maximum. Figures $14 \mathrm{c}$ and $\mathrm{d}$ are, for the winter season, also at the secondary heat flux maximum. These figures show that the intermediate-scale waves are very coherent but have a phase difference of approximately $100^{\circ}$. This means the intermediate-scale waves have winds and temperature anomalies that are almost completely out of phase. The most highly coherent waves have very similar phase differences. This relationship is seen in all seasons. Figure 15 is the wavenumberfrequency covariance spectra for the winter season. Figure 15 shows that wavenumber 2 , with a period of 8 days to 30 days, is responsible for the majority of the heat transport. Figure 14c shows the heat transport due to wavenumber 2 has no clear signal in coherence, as is seen for the intermediate-scale waves. Figure $14 \mathrm{~d}$
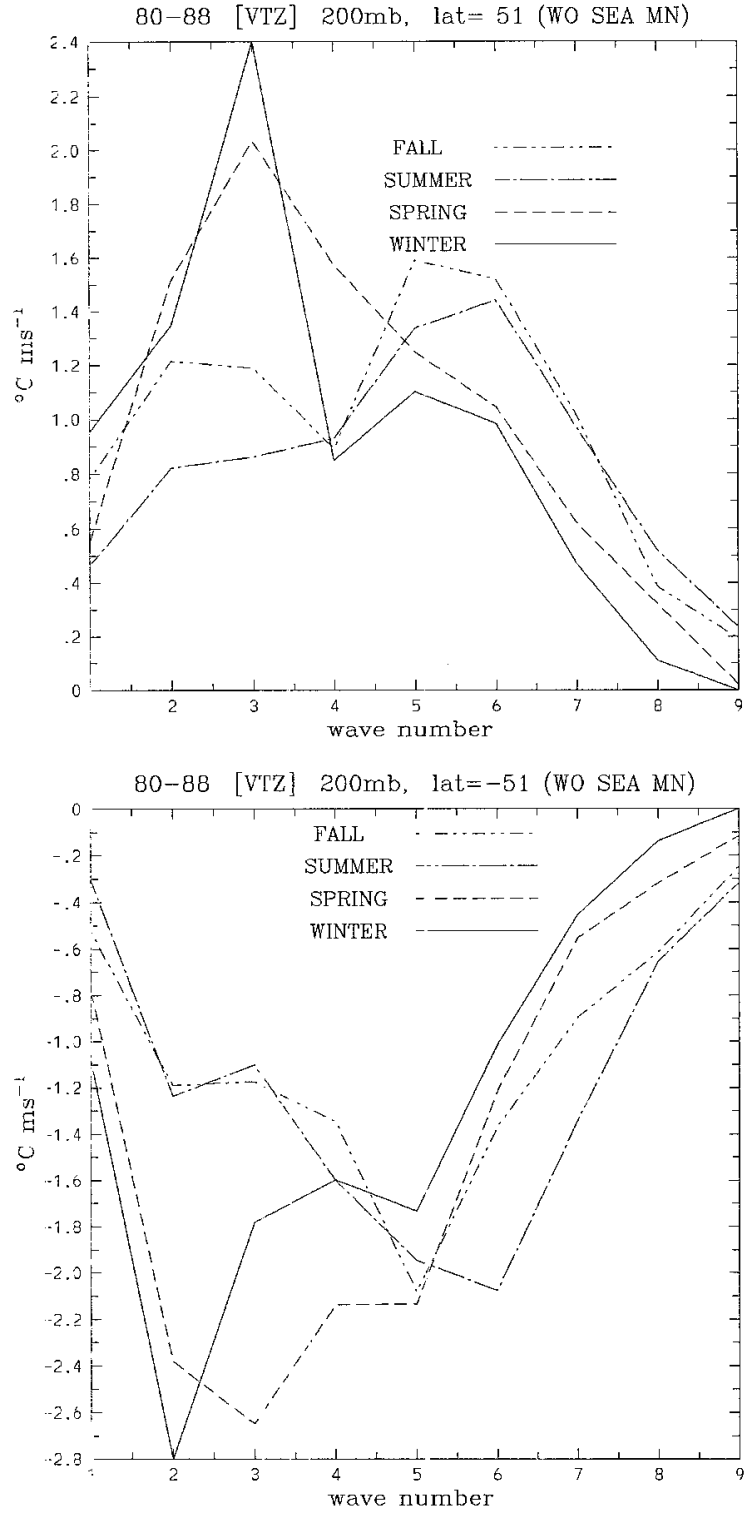

FIG. 11. The 1980-88 zonal mean transient eddy heat fluxes at $200 \mathrm{hPa}$, with seasonal means removed, as a function of zonal wavenumber: (a) heat fluxes at $51^{\circ} \mathrm{N}$, (b) heat fluxes at $51^{\circ} \mathrm{S}$.

shows that wavenumber 2 perturbations in wind and temperature are approximately $150^{\circ}$ out of phase. Therefore, the wavenumber 2 fields are much more in phase than the intermediate-scale waves that are so highly correlated.

\section{Summary and concluding remarks}

The waves responsible for the zonal mean heat transport at $850 \mathrm{hPa}$ have been shown to be of intermediate scale, highly coherent, and closely in phase. This result was found in both the Northern and Southern Hemispheres in all seasons. The annual cycle of the heat fluxes at $850 \mathrm{hPa}$ was shown to be due to the annual 

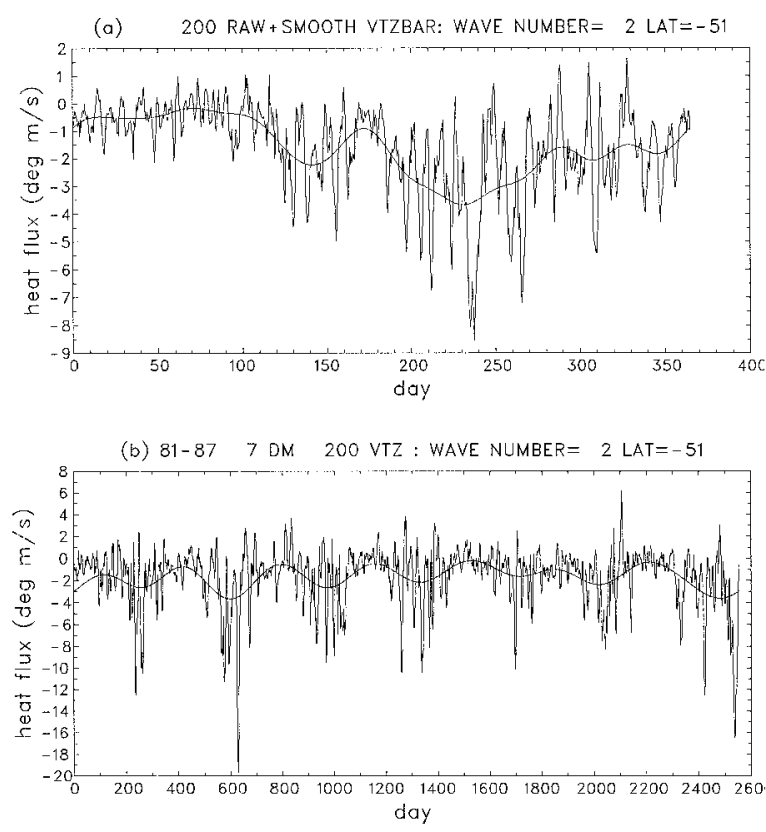

FIG. 12. Time series of the zonal mean transient eddy heat fluxes at $200 \mathrm{hPa}$ due to wavenumber 2 at $51^{\circ} \mathrm{S}$. The smooth curve is the raw data smoothed by applying a weighted Fourier series. (a) The 1980-88 annual cycle of the transient eddy heat fluxes. (b) The 198187 twice-daily transient eddy heat fluxes smoothed by applying a 7-day running mean average.

variations in wavenumber 4 and not due to a lengthening or shortening of the preferred scales of the waves.

The lifetime of the transient eddy heat fluxes in the Southern Hemisphere winter were found to be close to the lifetime predicted by the lifecycle study of SH. In the Southern Hemisphere summer the lifetimes of the transient eddy heat fluxes were shorter, which suggests that the baroclinic growth of the waves occurs over shorter time intervals when the temperature gradients are reduced. The lifetimes of the transient eddy heat flux in the Northern Hemisphere winter season at $850 \mathrm{hPa}$ was shown to be close to 6 days. The 6-day estimate for the lifetimes of the heat fluxes in the Northern Hemisphere winter and Southern Hemisphere summer are shorter than the lifetimes estimated by $\mathrm{SH}$ and RS. Farrell and Ioannou (1994) have argued that the lifetimes of the transient eddy heat fluxes are insufficient for modal dominance. They suggest that the observed heat flux is due to the transient development of nonmodal perturbations, not the exponential growth of modal instabilities.

At the secondary heat flux maximum, the intermediate-scale waves were found to be highly coherent but almost out of phase. The large-scale waves were found to transport the majority of the heat in the winter and spring in both hemispheres. These waves were found to have no clear coherence relationship between the perturbation winds and temperatures. The wind and temperature waves were found to be closely in phase.
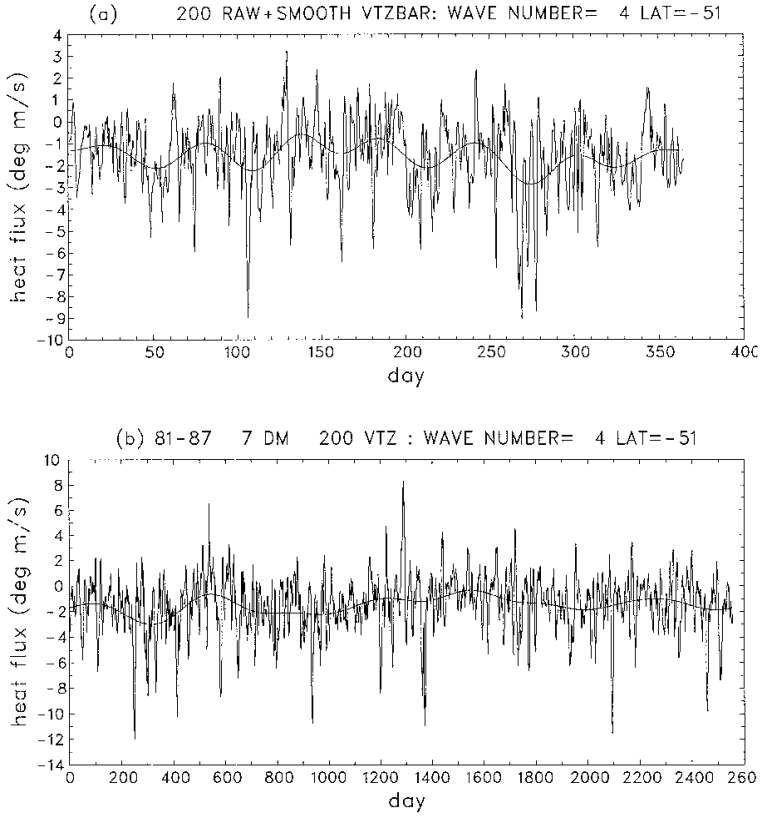

FIG. 13. Time series of the zonal mean transient eddy heat fluxes at $200 \mathrm{hPa}$ due to wavenumber 4 at $51^{\circ} \mathrm{S}$. The smooth curve is the raw data smoothed by applying a weighted Fourier series. (a) The 1980-88 annual cycle of the transient eddy heat fluxes. (b) The 198187 twice-daily transient eddy heat fluxes smoothed by applying a 7-day running mean average.

The phase and scale selection in both the Southern and Northern Hemispheres have been shown to be very similar. This is very interesting considering the differences in stationary wave forcing, zonal mean meridional temperature gradients, seasonal cycles, and baroclinic zones. The coherence and phase relationships of the large-scale waves in the Southern and Northern Hemisphere winter and spring seasons at the tropopause indicate that there may be a mechanism for baroclinic growth operating at the winter jet that is different from the mechanism responsible for the baroclinic growth at $850 \mathrm{hPa}$. It has been suggested by Dr. Arthur Hou (1995, personal communication) that this mechanism is the modulation of the strength and location of the subtropical winter jet by variability in the tropical Hadley circulation.

Acknowledgments. The ECMWF data used were provided by ECMWF. Part of this work was carried out while the author was a visitor at the Climate and Global Dynamics division at NCAR, which is funded by the National Science Foundation. The author would like to thank Kevin Trenberth, Peter Stone, and Nili Harnik for comments and discussions on the manuscript. Some of the statistical routines used were written by Dennis Shea of the CAS at NCAR. This research is partly sponsored by the Tropical Oceans Global Atmosphere Project Office under Grant NA87AANRG0208 and by NASA under NASA Order No. W-18,077. 

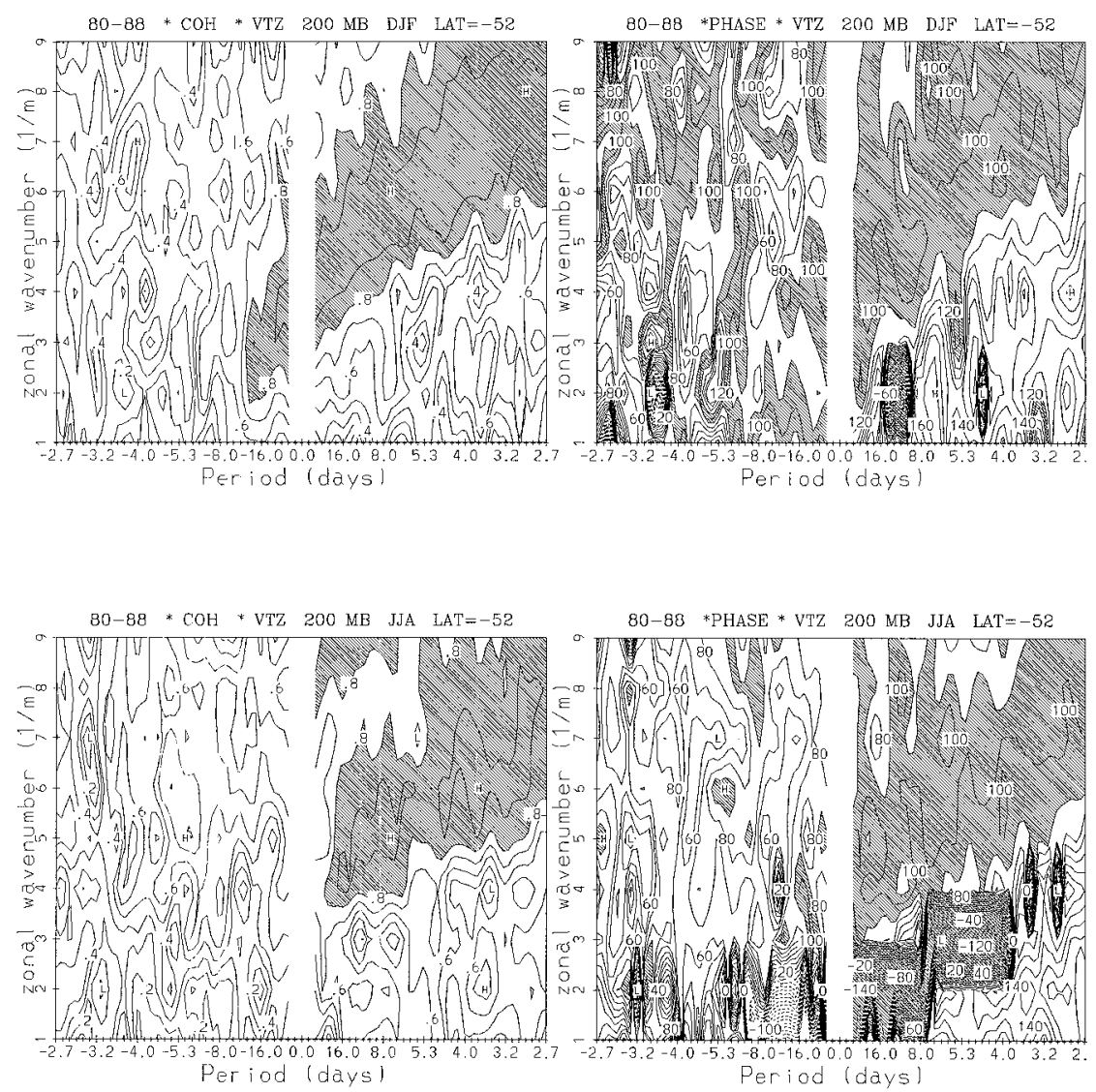

FIG. 14. The $1980-8851^{\circ} \mathrm{S}$ seasonally averaged wavenumber-frequency covariance of the transient eddy heat fluxes at $200 \mathrm{hPa}$. (a) Summer coherence (shaded region indicates coherence greater than 0.8). (b) Summer phase difference (shaded regions indicate phase difference between $90^{\circ}$ and $110^{\circ}$ ). (c) Winter coherence [same shading as in (a)]. (d) Winter phase difference [same shading as in (b)].

\section{REFERENCES}

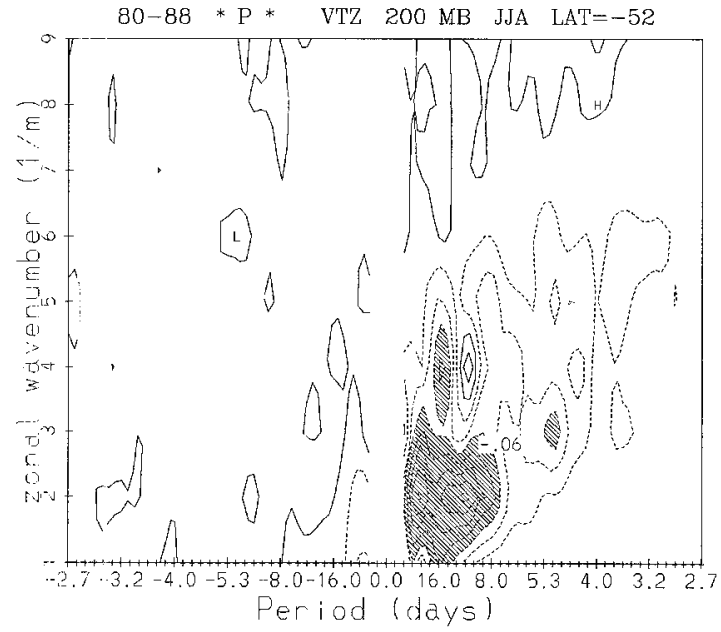

FIG. 15. The $1980-8851^{\circ} \mathrm{S}$ winter wavenumber-frequency covariance spectra of the transient eddy heat fluxes at $850 \mathrm{hPa}$.
Blackmon, M. L., 1976: A climatological spectral study of the 500 $\mathrm{mb}$ geopotential height of the Northern Hemisphere. J. Atmos. Sci., 33, 1607-1623.

Farrell, B. F., and P. J. Ioannou, 1994: A theory for the statistical equilibrium energy spectrum and heat flux produced by transient baroclinic waves. J. Atmos. Sci., 51, 2685-2698.

Fraedrich, K., and M. Lutz, 1987: A modified time-longitude diagram applied to $500 \mathrm{mb}$ heights along $50 \mathrm{~N}$ and 50S. Tellus, 39A, 2532.

Hamilton, K., 1983: Aspects of wave behavior in the mid and upper troposphere of the Southern Hemisphere. Atmos.-Ocean, 21, 4054.

Hayashi, Y., 1971: A method of analyzing transient waves by spacetime cross spectra. J. Meteor., 12, 404-408.

—, 1982: Space-time spectral analysis and its applications to atmospheric waves. J. Meteor. Soc. Japan, 60, 156-171.

Hurrell, J. W., and K. E. Trenberth, 1992: An evaluation of monthly mean MSU and ECMWF global atmospheric temperatures for monitoring climate. J. Climate, 5, 1424-1440.

Kao, S. K., and J. F. Sagendorf, 1970: The large-scale meridional transport of sensible heat in wavenumber frequency space. $\mathrm{Tel}$ lus, 22, 172-185.

Peixoto, J. P., and A. H. Oort, 1992: Physics of Climate. American Institute of Physics, $520 \mathrm{pp}$.

Randel, W. J., and J. L. Stanford, 1985a: An observational study of 
medium-scale wave dynamics in the Southern Hemisphere summer. Part 1: Wave structure and energetics. J. Atmos. Sci., 42, $1172-1188$.

— and - 1985b: The observed life cycle of a baroclinic instability. J. Atmos. Sci., 42, 1364-1373.

, and I. M. Held, 1991: Phase speed spectra of transient eddy fluxes and critical layer absorption. J. Atmos. Sci., 48, 688-697.

Salby, M. L., 1982: A ubiquitous wave 5 anomaly in the Southern Hemisphere during FGGE. Mon. Wea. Rev., 110, 1712-1720.

Simmons, A. J., and B. J. Hoskins, 1978: The life cycles of some non-linear baroclinic waves. J. Atmos. Sci., 35, 414-432.

Stone, P. H., S. J. Ghan, D. Spiegel, and S. Rambaldi, 1982: Shortterm fluctuations in the eddy heat flux and baroclinic stability in the atmosphere. J. Atmos. Sci., 39, 1734-1746.
Trenberth, K. E., 1984: Some effects of finite sample size and persistence on meteorological statistics. Part 1: Autocorrelations. Mon. Wea. Rev., 112, 2359-2368.

1992: Global analyses from ECMWF. NCAR Tech. Note NCAR/TN-373+STR, $191 \mathrm{pp}$.

van Loon, H., 1979: The association between latitudinal temperature gradient and eddy transport. Part 1: Transport of sensible heat in winter. Mon. Wea. Rev., 107, 525-534.

White, G. H., 1982: An observational study of the Northern Hemisphere extratropical summertime general circulation. J. Atmos. Sci., 39, 24-40.

Yu, W-B., R. L. Martin, and J. L. Stanford, 1983: Long and mediumscale waves in the lower stratosphere from satellite-derived microwave measurements. J. Geophys. Res., 88, 8505-8511. 